\title{
Foot Steps Power Generation using Mechanical System
}

\author{
S.V. Janugade ${ }^{1,}$ G.A. Yadav ${ }^{2}$, O.R. Mahadik ${ }^{3}$ \\ Assistant Professor, Mechanical Engineering, AGTI's Dr. Daulatrao Aher College of Engineering, Karad, India ${ }^{1,2}$ \\ U.G. Student, Mechanical Engineering, AGTI's Dr. Daulatrao Aher College of Engineering, Karad, India ${ }^{3}$
}

\begin{abstract}
In present day, power has become the fundamental need for human life. The availability and its conjunction is regarded as the index of national standard of living in the present day of civilization. Energy is an important input in all sectors of any countries economy. The objective of this project is to design a setup that leads to generating electricity the energy which is going waste when human climb the stairs. This human energy is utilized and converted into electrical energy. This generated energy is cost effective and nonhazardous for human. Power can be generated through stepping on the stairs, the generated power will be stored and can be used for domestic purpose. To obtain the above purpose, The experimental setup is designed which contains the structure, dome, rack, spur gear, bearings, flywheel, shaft, springs, chain drive and dynamo. The working principle is based on law of energy i.e mechanical energy is converted into electrical energy. When force is applied on footstep rack and spring get compressed therefore the pinion is rotated. This rotates the chain drive arrangement. The flywheel is coupled with chain drive to regulate the fluctuation and finally the dynamo is connected with the shaft. Thus reciprocating energy is converted into rotating energy and mechanical energy is converted into electrical energy. The energy generated is risk free and pollution free. The way of energy generation is eco friendly and nonhazardous to human. The output of energy increases as weight increases. The weight range is from 10 to $15 \mathrm{~kg}$. The LED bulb blows is of 9 watt and the rang of voltage obtained is from 8 to $35 \mathrm{v}$ as per the changes in weight. The electricity is produced in low budget when mass production and installation is done. The required area is low, no obstructions in traffic, easy maintenance and construction.
\end{abstract}

Keywords: Foot step Energy, Eco friendly Power.

\section{INTRODUCTION}

In the present scenario, power has become the thermal energy conversions) etc. for power generation. fundamental need for human life. The availability and its This work generates electric power by simply walking or per capita consumption is regarded as the index of national running on footsteps. In order to develop a technique to standard of living in the present day civilization. Energy is harness footstep energy, a foot step electricity generating an important input in all sectors of any countries economy. device was developed in the Reactor Control Division, Energy crisis is due to two reasons, firstly the population BARC. of the world has been increasing rapidly and secondly the standard of living of human beings has also increased. India is a country, which majorly suffers with lack of sufficient power generation. The capital energy consumption of U.S.A. is about 8000 K.W.H, where as in India it is only 150 K.W.H. U.S.A. with only $7 \%$ of the world's total population consumes about $32 \%$ of total power generated where as India a developing country with $20 \%$ of world population consumes only $1 \%$ of total energy generated in the world. The regular conventional fossil fuels are the main sources for power generation, but there is a fear that they will get exhausted eventually in the next few decades. Therefore investigate some alternative, new sources for the power generation, which will not deplete in the next few years. Another major problem is pollution. It affects all living organisms. Therefore investigate other types of renewable sources, which produce electricity without using any commercial fossil fuels. Already there are such systems using renewable energy such as solar energy, wind energy, OTEC (ocean

\section{PRESENT THEORY AND PRACTICES}

Siba brata Mohanty et al [1] Proposal for the utilization of waste energy of foot power with human locomotion is very much relevant and important. Man has needed and used energy at an increasing rate for his sustenance and well-being ever since he came on the earth a few million years ago. With further demand for energy, man began to use the wind for sailing ships and for driving windmills, and the force of falling water to turn water for sailing ships and for driving windmills, and the force of falling water to turn water wheels. Till this time, it would not be wrong to say that the sun was supplying all the energy needs of man either directly or indirectly and that man was using only renewable sources of energy.

S.D.Mendhule et al [2] various countries draw a large amount of energy from a variety of sources and can be categorized as conventional and non-conventional source 
IARJSET

of energy. The main sources are Fossil Fuel Energy, converted into rotating motion of the pinion and when Nuclear Energy and Hydraulic Energy. Among these, the force gets released it goes on its initial position. The fossil fuels are used to generate energy in more than $85 \%$ of all energy sources.

Aniket Mishra et al [3] the energy generated and produce power by using the speed breaker as power generating unit. The kinetic energy of the moving vehicles can be converted into mechanical energy of the shaft through rack and pinion mechanism. Then, this mechanical energy will be converted to electrical energy using generator which will be saved with the use of a battery. The energy we save during the day light can be used in the night time for lighting street lights.

A. Adhithan et al [4] operation of a combustion engine and in urban areas, there is a large amount of electromagnetic energy in the environment because of radio and television broadcasting. Over the past two decades, there has been significant interest in converting mechanical energy from human motion into electrical energy. This electrical energy can then be used to Recharge batteries in electronic devices or directly power small scale, Low-power circuits. A number of commercial devices use human power to produce Electricity such as hand-crank generators (for powering Flashlights, radios, and recharging mobile devices), and pedal Generators (that can be used to power larger electrical devices typically generating between 100 and $1000 \mathrm{~W}$ and can be as high As $1000 \mathrm{~W})$. However, these generators require concentrated human Effort for long periods of time, which might preclude the User from doing other tasks.

sprocket arrangement on the same shaft is connected with the other sprocket with the help of chain drive to transfer the energy. Flywheel is coupled with the sprocket to regulate the fluctuation in the energy and finally dynamometer is connected with the shaft which shows the output by converting the mechanical energy into electrical energy.

The various machine elements used in the construction of power hump are Structure, Dome, Rack, Bearings, Flywheel, Shaft Spring, Chain drive Dynamo

\begin{tabular}{|c|c|c|}
\hline Part & $\begin{array}{c}\text { Material } \\
\text { Used }\end{array}$ & Specification \\
\hline $\begin{array}{c}\text { STRUCTURE } \\
\text { (L-angle) }\end{array}$ & Mild steel & $25 \times 25 \times 5 \mathrm{~mm}$ \\
\hline $\begin{array}{c}\text { STRUCTURE } \\
\text { Sheet metal }\end{array}$ & Mild steel & $720 \times 480 \times 4 \mathrm{~mm}$ \\
\hline Shaft & Mild steel & $\varnothing 16 \mathrm{~mm}$ \\
\hline Spring & Mild steel & $\begin{array}{c}\mathrm{D}=30 \mathrm{~mm}, \mathrm{~d}=5 \mathrm{~mm}, \\
\mathrm{~N}=15, \mathrm{Nt}=17\end{array}$ \\
\hline Flywheel & Mild steel & $\begin{array}{c}\varnothing 200 \mathrm{~mm}, \text { thickness }= \\
15 \mathrm{~mm}\end{array}$ \\
\hline & & $\begin{array}{c}\text { External diameter } \\
=150 \mathrm{~mm} \text { Internal } \\
\text { diameter }=40 \mathrm{~mm}\end{array}$ \\
\hline Sprocket & Mild steel & 12 volts D.C. \\
\hline Dynamometer & Assembly & \multicolumn{2}{|c|}{} \\
\hline
\end{tabular}

\section{D view of working model}

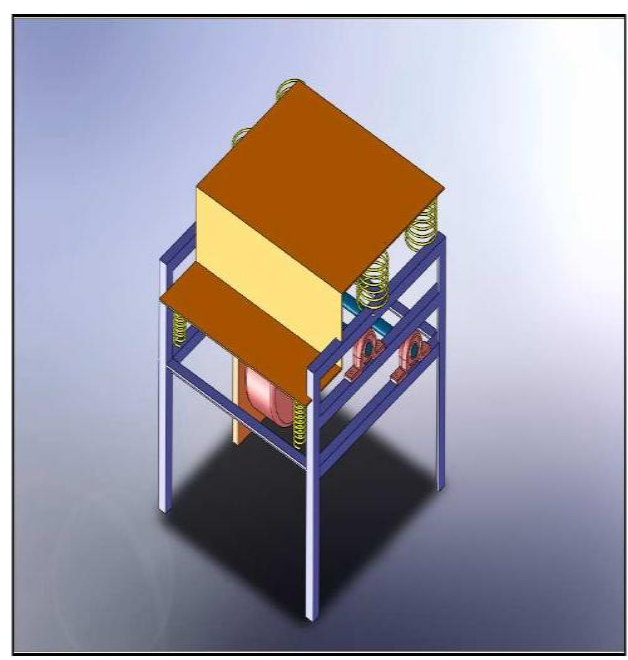

\section{MANUFACTURING}

\section{Structure}

It is an assemblage of a number of resistant bodies having no relative motion between them. Structures are meant for taking up loads. There is only straining action due to forces acting on them.

No useful energy is transmitted by it. While working, the machine structure is subjected to both static and dynamic forces, therefore it is essential that the structure should not deform or vibrate beyond the permissible limits under the action of these forces.

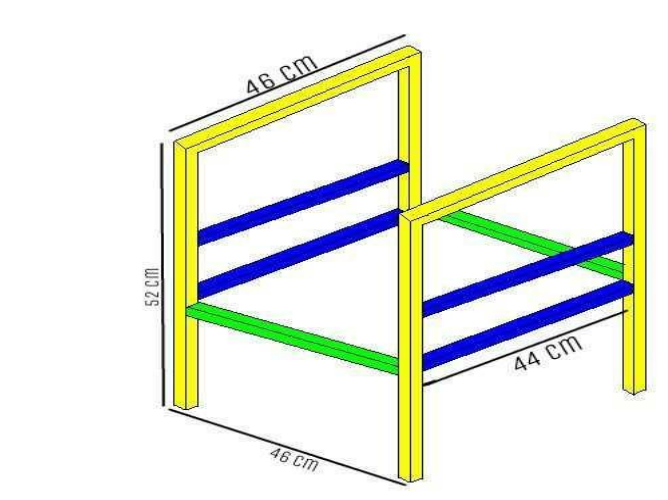

Working principle

Working principle is based on the law of energy i.e. Mechanical energy is converted in to electrical energy. When the force is applied on the foot step, springs gets compressed and the energy passes vertically through the rack arrangement and the reciprocating movement 
IAR JSET

International Advanced Research Journal in Science, Engineering and Technology

National Conference on Design, Manufacturing, Energy \& Thermal Engineering (NCDMETE-2017) AGTI's Dr. Daulatrao Aher College Engineering, Vidyanagar Extension, Karad

Vol. 4, Special Issue 1, January 2017

\section{MACHINE PHOTOGRAPHS}

\section{Photographs}

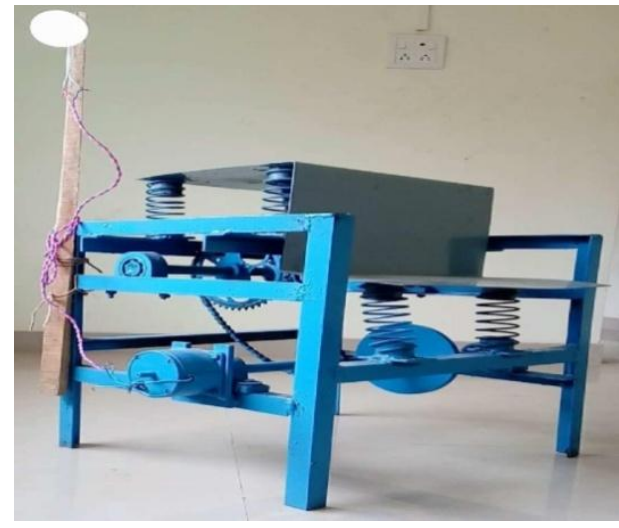

\section{Experimental investigation:}

For investigating working of experimental setup case study is taken for primary school student

\section{WEIGHING M/C:}

The weighing machine used in the experiment is analog type. the range of the weighing machine is

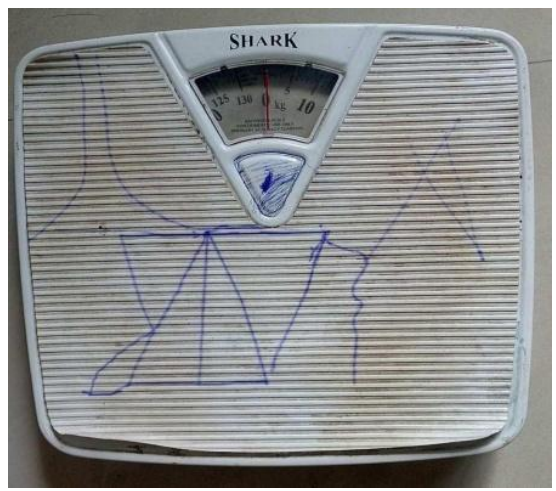

MIN: 5kg, MAX: 130kg, ERROR: 500g

\section{DIGITAL MULTIMETER:}

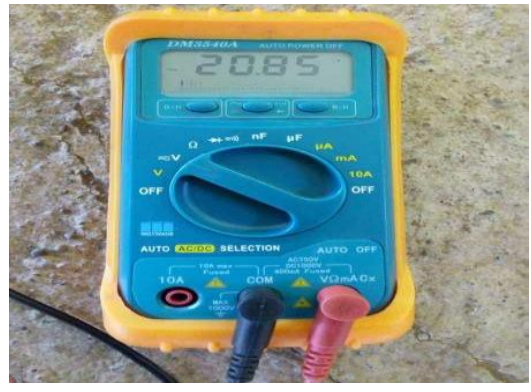

Range: $3.2 \mathrm{~V}$ to $750 \mathrm{~V}$

Accuracy: $(1.2 \%+5)$ digit

Resolution: $1 \mathrm{mV}$ to $1 \mathrm{~V}$

Input resistance: Auto AC/DC:2M

Manual:6M

\section{LED BULB:}

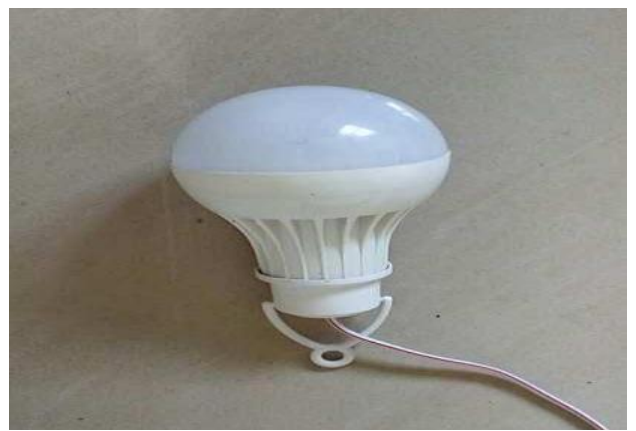

WATTAGE: 9 WATT

VOLTAGE: $220 \mathrm{~V}$

LIFE: 35000 Hrs POWER SUPPLY: AC

MAX VOLTAGE PROTECTION: $320 \mathrm{~V}$

\section{CASE STUDY}

\begin{tabular}{|c|c|c|c|}
\hline Case & $\begin{array}{c}\text { Human } \\
\text { weight in }\end{array}$ & $\begin{array}{c}\text { Bulb } \\
\text { Position }\end{array}$ & $\begin{array}{c}\text { Voltage } \\
\text { generated }\end{array}$ \\
\hline 1 & 50 & ON & 35.5 \\
\hline 2 & 35 & ON & 21.43 \\
\hline 3 & 28 & ON & 18.05 \\
\hline 4 & 25 & ON & 16.28 \\
\hline 5 & 12 & ON & 8.59 \\
\hline
\end{tabular}

\section{ADVANTAGES DISADVANTAGES, APPLICATIONS}

\section{Advantages}

- Low budget electricity production. Less floor area

- Easy construction. Less number of parts required. Electricity can be used for many purposes.

- No obstruction to traffic. Easy maintenance. Suitable at parking of multiplexes, malls, toll booths, signals, etc. It can be use at any time when it necessary.

\section{Disadvantages}

- Output. Initial investment is high.

- It gives low electricity

\section{Applications}

Charging batteries and using them to light street lamps, etc. Used in malls, where so many people move about round the clock. In LED lights for specific purposes.

In air circulation system for rooms, by small fans. For use in security alarms, etc. 
IAR JSET
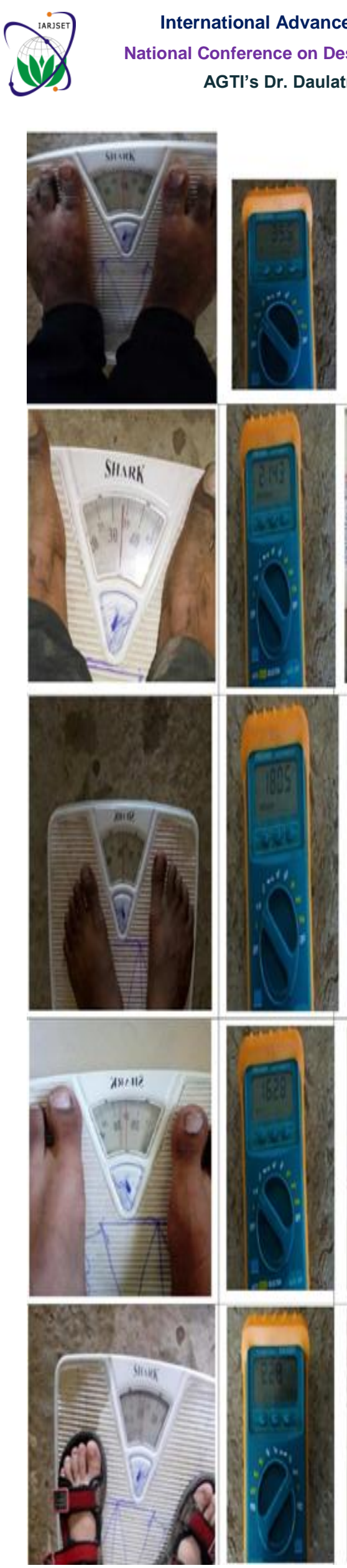

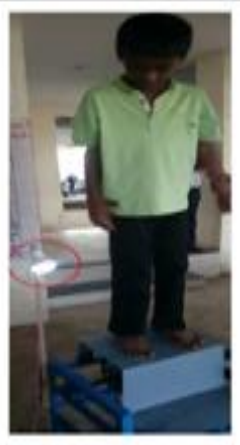

Vol. 4, Special Issue 1, January 2017
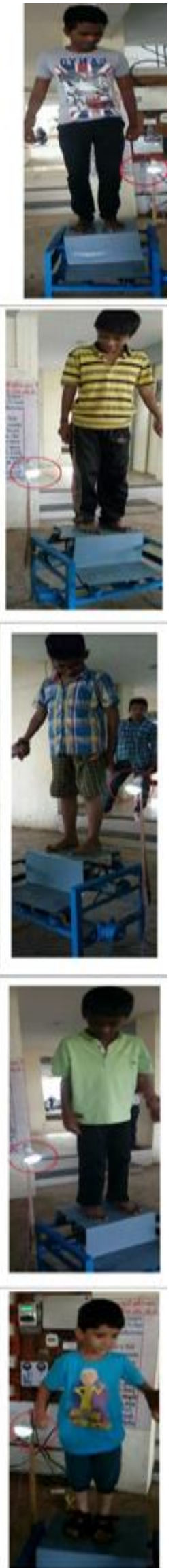

\section{RESULT:} setup.
RESULT AND CONCLUSION

1. When human climb the stairs that human energy is converted in to electrical energy by using the experimental

Case 1: At $50 \mathrm{~kg}$ load the voltage generated is $35.5 \mathrm{~V}$ Case 2: At $35 \mathrm{~kg}$ load the voltage generated is $21.43 \mathrm{~V}$ Case 3: At $28 \mathrm{~kg}$ load the voltage generated is $18.05 \mathrm{~V}$ Case 4: At $25 \mathrm{~kg}$ load the voltage generated is $16.28 \mathrm{~V}$ Case 5: At $12 \mathrm{~kg}$ load the voltage generated is $8.59 \mathrm{~V}$

2. The experimental setup is not hazardous for human

3. It is cost effective when continuously used

\section{Graphical representation:}

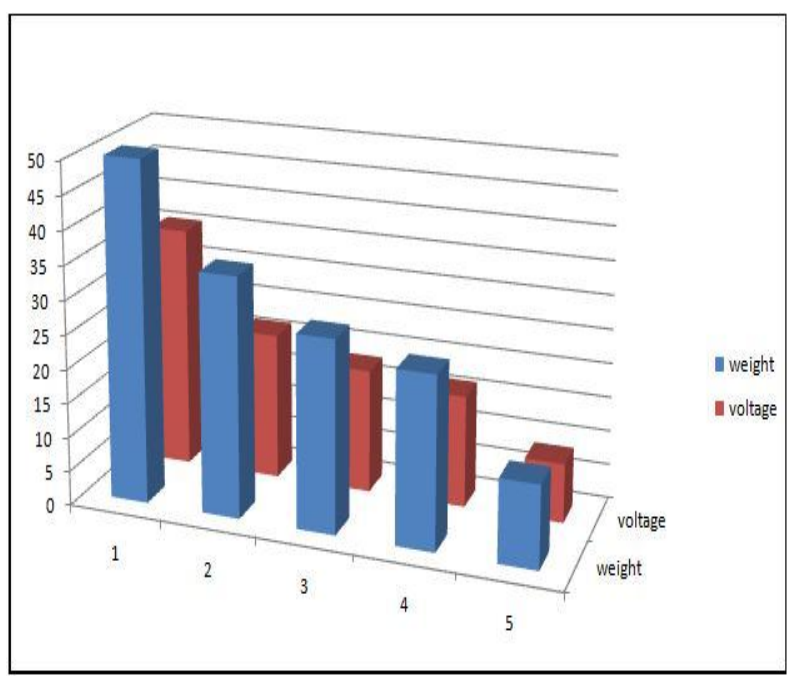

Figure- Weight vs. Voltage

\section{Explanation:}

As weight increases the voltage obtained also increases. The weight range is taken from 10 to $50 \mathrm{~kg}$ which gives electricity output in terms of voltage and blows the led bulb of 9 watt.

\section{CONCLUSION}

The experimental setup gives the risk free energy generation. The energy which is going waste when human climbing the stairs is utilized and converted into electrical energy. It is cost effective when continuously used. it can be installed at crowdie areas such as malls, bus stand, railway station, school, collages etc. This method generates the electric power without polluting environment. The waste energy supplied by human is utilized in this system. This energy source is continuous and renewable. Moreover confident that this method of power generation will be used for rural electrification and to fulfill power needs. Also this system looks very eco friendly from the environmental point of view. The proposed work "Electrical Power Generation through 
footsteps" has been successfully tested and it is the best economical, affordable energy solution to common people.

\section{FUTURE SCOPE}

This Project can be further employed in speed breakers. Where the rack gear is assembled under the dome and the entire mechanism is constructed below the road. This concept can also apply at the crowdie areas and output measure per hour, per week or per month.

\section{REFERENCES}

1. Siba brata Mohanty, Sasank shekhar Panda, "An Investigation on Generation of Electricity Using Foot Step", International Journal of Engg. Sciences \& Reserch Technology, May, 2014.

2. S.D.Mendhule, V.K.Knkal, P.M.Badwe, "Electricity Generation from Footstep: A Review", International Journal of Engg. Applicatons \& Reserch Technology, oct 2013.

3. Aniket Mishra, Pratik Kale, "Electricity Generation from Speed Breakers," The International Journal of Engineering And Science, Vol. 2, Issue 11, Pages 25-27, 2013.

4. A.Adhithan1, K.Vignesh2, M.Manikandan, "Proposed Method of Foot Step Power Generation Using Piezo Electric Sensor", International Advanced Research Journal in Science, Engineering and Technology, Vol. 2, Issue 4, April 2015.

5. Alok Kumar Singh, Deepak Singh, Madhawendra Kumar, Vijay Pandit, Prof.Surendra Agrawal, "Generation of Electricit through Speed Breaker Mechanism," Satyam Education \& Social Welfare Socie ty Group of Institution Bhopal,vol.2 issued April 2013 ,ISSN :2319-1058

6. Wail Adaileh, Khaled Al-Qdah, Mayyas Mahasneh, Potential of Power Generation Utilizing Waste Kinetic Energy from Vehicles, Smart Grid and Renewable Energy, 2012, 3, 104111doi:10.4236/sgre.2012.32015 Published Online May 2012 